\title{
Effects of feeding Beta vulgaris saccharifera bulb for fattening desert lambs under tropical conditions of Sudan
}

\author{
M D Mohammed ${ }^{1}, \mathrm{~K}$ M Elamin², A E Amin, H E Hassan ${ }^{4}$, A F Khalid ${ }^{5}$
}

1. Department of Animal Nutrition, Faculty of Animal Production (Managil), University of Gezira, Wad Medani, Sudan,P.O.20. 2. Department of Animal Breeding, Faculty of Animal Production (Managil), University of Gezira, Wad Medani, Sudan,P.O.20. 3. Department of Veterianary Medicine, Pharmacology and Toxicology, Faculty of Veterinary Medicine, University of Khartoum, Shambat, Sudan.

4. Department of Meat production and Technology, Faculty of Animal Production (Managil), University of Gezira, Wad Medani, Sudan,P.O.20. 5. Department of Dairy production

Faculty of Animal Production (Managil), University of Gezira, Wad Medani, Sudan

Corresponding author: K M Elamin, email:khalid1130@yahoo.com

Received: 21-12-2011, Accepted: 18-01-2012, Published Online: 10-03-2012

doi: $10.5455 /$ vetworld.2012.330-334

\begin{abstract}
Aim: The objective of this study was to evaluate the effects of introducing Sugar Beet bulb as a cheap substitute for grains in rations formulated for sheep fattening.

Materials and Methods: This trial was conducted at the Experimental unit of Rural Development and extension center, Faculty of animal production, University of Gezira. Twenty four Sudanese desert lambs (Ashgur ecotype) were purchased from local markets to assess the effects of replacing grain with Sugar Beet (Beta vulgaris saccharifera) Bulb on feed lot performance, carcass traits under tropical conditions of Sudan. Sugar Beet bulb was incorporated in three rations with a control ration (A: control, B, C, D) at percentages of $0,11,22$, and 33.

Results: The results showed that total weight gain and daily feed intake in group $\mathrm{D}$ were significantly different at $(\mathrm{P}<0.05)$ where values of $5.59 \pm 1.73$ and $0.94 \pm 0.13 \mathrm{~kg}$ were recorded. Total weight gain, daily dry matter intake, daily energy intake and feed conversion ratio were in the range of 10.67- 5.59, 1.03-0.83, 0.33-0.27and 11.77- 7.70 kg respectively. Treatments showed no significant differences at $(\mathrm{P}<0.05)$ for slaughter weight, empty body weight, dressing \% on slaughter weight basis and dressing \% on empty weight basis, the obtained results for these traits were 27.78-25.37, 24.76- 22.22, 45.80-43.45\% and 51.41- 49.65\%. Carcass cuts (Leg, Loin, Rack, Plate and Neck \& shoulder) weight and percentages showed no significant differences among treatments.

Conclusion: It is concluded that replacing expensive grains with Beta vulgaris bulb can be practiced in sheep fattening project up to $22 \%$ with excellent results.
\end{abstract}

Keywords: Dressing, Grain, Tenderness, Weight gain

To cite this article: Mohammed MD, Elamin KM, Amin AE, Hassan HE and Khalid AF (2012) Effects of Feeding Beta vulgaris saccharifera Bulb for Fattening Desert lambs under tropical conditions of Sudan, Vet World 5(6): 330-334, doi: 10.5455/vetworld.2012.330-334

\section{I ntroduction}

Sudan is predominately an agricultural country. Livestock population was estimated as 140 million head of which 41.1 million head of cattle, 43.1 million head of goat, 51.1 million head of sheep and 4.4 million head of camel [1]. Of these livestock species, sheep is characterized by economic importance as it has good productive and reproductive merits over members of the family Bovidae [2]. In recent years, there is a dramatic increase in the cost of energy sources parallel to the increase in demand for animal feeds. This situation encouraged the nutritionist to search for cheaper high energy feed ingredients [3].
Many attempts have been made to introduce unconventional new forages; especially for the summer season when animals are underfed [4]. Sugar beet is a fleshy root crop grown usually for sugar production [5]. It is native to temperate countries and hence had been associated with temperate environment. Despite being a temperate crop, Sugar beet trials have been going on in some selected tropical countries (e.g. India and South Africa) [5].

The objective of this study was to evaluate the effects of introducing Sugar Beet bulb as a cheap substitute for grains in rations formulated for sheep fattening. 


\section{Materials and Methods}

Study location: The experiment was conducted at Rural development and extension center (University of Gezira) and it extended for ten months.

Experimental House: The animals were lodged in the Animal House at the Extension and Rural Development Centre, Faculty of Animal Production, University of Gezira Managil. The house was $7 \times 9 \mathrm{~m}$ and was bounded by metal sheets $2 \mathrm{~m}$ in height set over a half-meter brick wall. Internally the house was divided into 8 pens and two of them left as a service area. Each pen was $2 \times 3 \mathrm{~m}$. and has a separate door and equipped with a metal feed trough and a plastic water container. The roof was made of corrugated metal sheets, slopping from the middle $(3-2.5 \mathrm{~m})$ to the side, supported with metal pipes. The ground was made of concrete with reasonable inclination for drainage.

Experimental animals: Authors followed the "International Animal Ethics Committee guideline" for use of animals in the study. Animals used in this study belong to Sudan desert sheep (Ashugr ecotype).Twenty four animals at average age of 3-4 month were purchased from local market, then transported to location of study.The animals were rested, watered, and then ear-tagged and treated against internal parasites using albendazole. They were also treated for external parasites using topical pyrithrins (Cyper-methrine spray, Cyper, Holland). The Animals were offered the control feed for adaptation during the first two weeks. Then, the animals were weight-distributed and randomly allotted to four treatments A, B, C and D, 6 lambs per treatment. The experiment lasted for 10 weeks.

Table 1. Percent inclusion rates of ingredients (as fed) And chemical composition (dry matter basis) of experimental diets

\begin{tabular}{lllll}
\hline Ingredients & A & B & C & D \\
\hline Sorghum & 33 & 22 & 11 & - \\
Sugar Beet Bulb & - & 11 & 22 & 33 \\
Molasses & 14 & 16 & 16 & 15 \\
Groundnut meal & 6 & 11 & 12 & 15 \\
Cottonseed meal & 15 & 09 & 09 & 05 \\
W. Bran & 12 & 11 & 12 & 15 \\
Groundnut hulls & 15 & 15 & 13 & 12 \\
NaCl & 01 & 01 & 01 & 01 \\
Vitamin /mineral & 04 & 04 & 04 & 04 \\
CP \% & 14.04 & 14.31 & 14.06 & 14.33 \\
Energy (Mcal ME /kg) & 2.32 & 2.32 & 2.33 & 2.34 \\
Energy /Protein ratio & $1 / 6$ & $1 / 6$ & $1 / 6$ & $1 / 6$ \\
\hline
\end{tabular}

Animal Feeding: Four isocaloric ( $10 \mathrm{MJ} \mathrm{ME} / \mathrm{kg}$ ) and isonitrogenous $(14 \% \mathrm{CP})$ rations were formulated (Table 1), meeting the nutritional requirements of desert lambs [6]. The rations were labeled as treatment
A, B, C and D. Dietary formulae utilized sorghum grains and sugar beet bulb inversely replacing each other for the total of $33 \%$ energy supplying ingredients. Ration A served as the control ration. The different rations were offered ad labium and fresh clean water was available all the time. Experimental feeding was continued up to ten weeks and then the animals were slaughtered for carcass assessment.

Data Collection: Feed intake (kg/group) was recorded daily by calculating the difference between offered feed and refused one. Weekly weights for each animal within the different groups were recorded to the nearest $0.5 \mathrm{~kg}$. Animals were weighed at 7:0 am before feeding.

Two animals of each experimental treatment were selected randomly for slaughter at the slaughter Platform. The animals were fasted overnight and had access to water prior being slaughtered according to the Muslim practice. The animals were weighed and then the slaughter weight was recorded. Appendages (head, tail, skin and feet) were weighed each separately. The animal then was eviscerated on a full linea alba incision. Visceral organs, (liver, spleen, kidney, pancreas, intestines full and empty, omental fats and genitals) and Pluck (Heart, lungs and trachea and diaphragm), were separated each and weighed. Kidney knob and channel fat were collected and weighed. The alimentary tract was weighed full and then empty to calculate the contents (fill). The fill was subtracted from the slaughter weight to obtain the empty body weight (EBW). Warm carcass weight was recorded. Then the warm carcass was split into right and left halves by sawing along the vertebral column. Each half was weighed separately. The left half was then divided into fore and hind saddles cutting between the 12th and 13th rib. The hind saddle was further dissected into two wholesale cuts (leg and loin) by cutting proximal to ala of the os ileum of the pelvic girdle. The fore saddle was separated into two anterior and posterior parts between the 5th and 6th ribs. The anterior part was separated into two cuts neck and shoulder and brisket and foreshank by cutting mid distance horizontally parallel to the vertebral column. The posterior part was separated also into two cuts rack (upper) and plate (lower) by cutting mid distance horizontally parallel to the vertebral column. The weight of each commercial cut was recorded [7].

Meat samples for sensory evaluation were taken from the Longissimus dorsi muscle over the loin region of the right half and were kept in a deep freezer till organoleptic evaluation. Test samples were thawed at $30^{\circ} \mathrm{C}$ for 1 hour, wrapped in an aluminum foil paper 
Effects of Feeding Beta vulgaris saccharifera Bulb for Fattening Desert lambs under tropical conditions of Sudan

Table-2. Analysis of variance and average (mean \pm SD) performance values of lambs fed different levels of sugar beet bulb for $\mathbf{7 0}$ days.

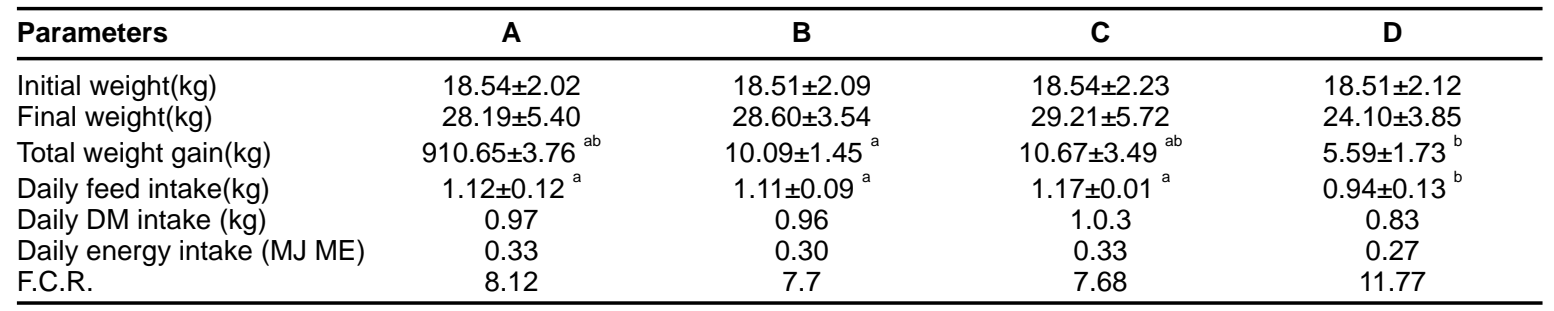

Means in a row bearing the same letter or no letter subscript are similar ( $p>0.05)$

Table-3. Analysis of variance and average (mean \pm SD) of Slaughter weight, Empty body weight , dressing out percentages on empty body and slaughter weight basis of lambs fed different levels of sugar beet bulb for 70 days.

\begin{tabular}{lcccc}
\hline Parameters & A & B & C & D \\
\hline Slaughter weight & $25.37 \pm 0.69$ & $27.78 \pm 12.93$ & $27.48 \pm 4.87$ & $25.52 \pm 4.82$ \\
Empty body weight & $22.27 \pm 0.28$ & $24.75 \pm 6.28$ & $24.76 \pm 3.46$ & $22.22 \pm 4.69$ \\
Dressing \% (slaughter weight basis) & $45.11 \pm 0.66$ & $43.74 \pm 2.75$ & $45.80 \pm 1.35$ & $43.45 \pm 0.72$ \\
Dressing\%(empty body weight basis) & $51.41 \pm 0.79$ & $49.65 \pm 1.51$ & $51.31 \pm 0.72$ & $50.06 \pm 1.28$ \\
\hline
\end{tabular}

Means in a row are similar $(p>0.05)$.

and cooked in an electric oven at $300{ }^{\circ} \mathrm{C}$ for ten minutes. Five panelists were selected randomly out of ten who are trained on the sensory procedure. Cooked meat samples were served warm in small pieces randomly to panelists. The panelists were asked to score color, tenderness, flavor and juiciness out of an eight sensory evaluation unit scale. Water was used by panelists for masking taste.

Statistical Analysis: Data was subjected to SPSS program version 10 .

\section{Results and Discussion}

Table 2 shows average performance values of Desert lambs fed different levels of sugar beet bulbs for 70 days. Initial body weight for Ashugr sheep at about 4 month of age ranged from 18.54 to 18.51 . These findings were lower than the results reported by [8] for body weight in Awassi lambs at same age (26.05-30.66 kg) and by [9] who reported 24.6- 24.97 $\mathrm{kg}$. Normal values for initial weights of experimental groups exhibit insignificant variations in weight due to different backgrounds of breeds, breeding systems, raising conditions and nutritional experience. Final body weight at 7 month of age in this study was 29.21$24.10 \mathrm{~kg}$ which is lower than the results depicted by Mousa [8] in Awassi lambs (36.86-40.06 kg) and by [9] who reported $42.46-49.86 \mathrm{~kg}$. The final weights as they were statistically similar, but the trend is that it increases at low and medium beet bulb replacements (11-22\%) and decreases below the control at maximum beet bulb replacement $(33 \%)$.
Total weight gain was in the range of 10.67-5.59 $\mathrm{kg}$. This finding is similar to that reported by [10] for Sudan desert sheep for 45 days $(5.30-8.59 \mathrm{~kg})$ and [11] for desert sheep (9.84-11.49 $\mathrm{kg}$ ) but lower than the results reported by [8] in Awassi lambs for 90 days $(13.48-15.65 \mathrm{~kg})$. Treatments significantly $(\mathrm{p}<0.05)$ affected total weight gain as ration $\mathrm{A}$ and $\mathrm{C}$ showed highest gain and ration $\mathrm{D}$ gave the lowest gain. Daily feed intake in this trial was $1.17-0.94 \mathrm{~kg}$. This is in accordance with the findings reported by [9] in Awassi lambs $(1.123-1.186 \mathrm{~kg})$., [12] who reported $1.06-$ $1.10 \mathrm{~kg}$, [10] who reported $0.98-1.26 \mathrm{~kg}$, [11] who reported $1.14-1.35 \mathrm{~kg}$ [9] who reported $0.932-1.030$ $\mathrm{kg}$. This is lower than the results reported by [13] who reported $1.40-1.35$, and [14] who reported 1.32 $1.01 \mathrm{~kg} /$ day in Sudan desert sheep.

Treatments significantly $(\mathrm{p}<0.05)$ affected feed intake as ration D practiced the lowest intake. Daily dry matter intake and daily energy intake showed no significant $(\mathrm{p}<0.05)$ difference among treatments.

Feed conversion ratio in this study is 8.12- 7.68 which is in agreement with the results reported by [14] who found a range of 8.74 to 6.48 and [13] who reported $7.63 \mathrm{kgfeed} / \mathrm{kh}$ gain. Treatments showed no significant differences.

Table-3 shows average dressing out percentages on slaughter weight and on empty body basis values of Desert lambs fed different levels of sugar beet bulbs for 70 days. Treatment effect was not significant ( $>0.05)$ on slaughter and empty body weights and also in dressing percentages on both slaughter and 
Effects of Feeding Beta vulgaris saccharifera Bulb for Fattening Desert lambs under tropical conditions of Sudan

Table-4. Analysis of variance and average (mean \pm SD) weights $(\mathrm{kg})$ of carcass cuts and their percentages out of the warm carcass of lambs fed different levels of sugar beet bulb for 70 days

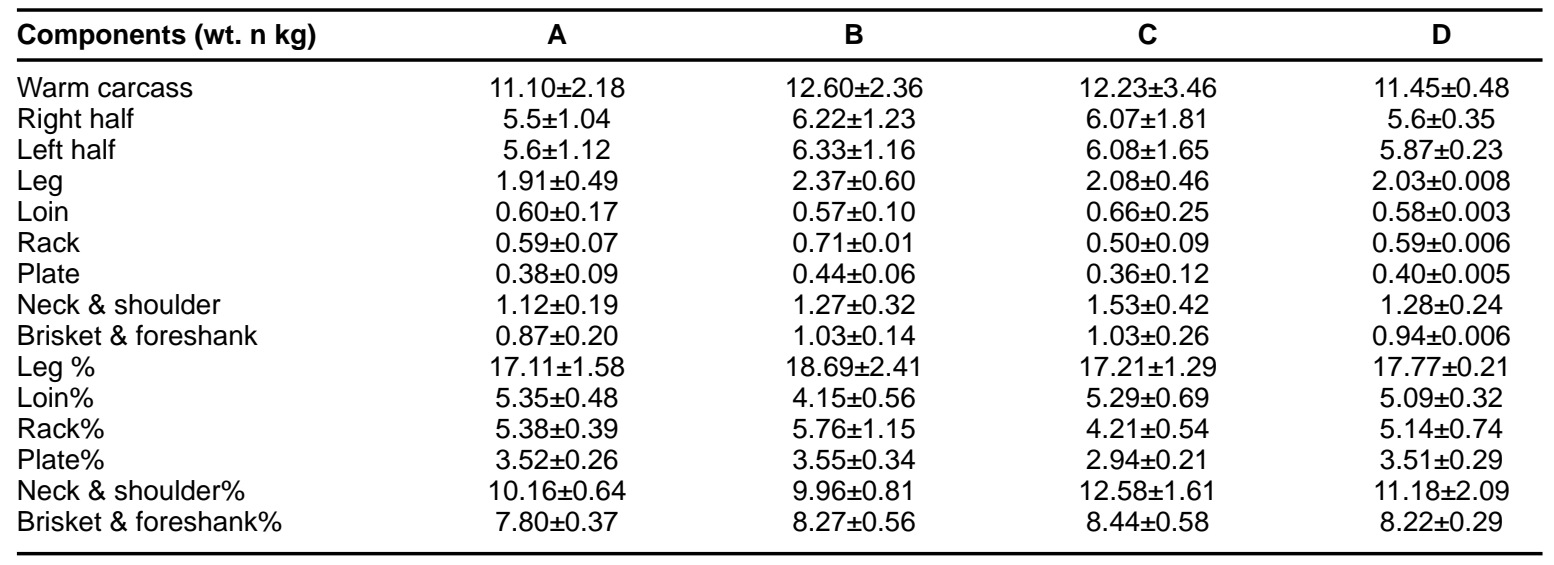

Means in a row bearing the same letter or no letter subscript are similar $(p>0.05)$.

Table-5. Average subjective assessment values of meat quality attributes of lambs fed different levels of sugar beet bulb for $\mathbf{7 0}$ days.

\begin{tabular}{lcccc}
\hline Parameters & A & B & C & D \\
\hline Tendernes\% & 100 & 86.7 & 80 & 80 \\
Flavor \% & 100 & 100 & 100 & 100 \\
Color \% & 100 & 100 & 100 & 100 \\
Juiciness \% & 93.3 & 86.7 & 80 & 80 \\
\hline
\end{tabular}

empty body weight basis. Dressing percentage value on empty body weight basis ranged from 51.41to $49.56 \%$. This is in agreement with [15] and [13], but higher than the results reported by [16].

Table- 4 shows average weights of carcass cuts and their percentages out of the warm carcass. Treatment effect was significant $(\mathrm{p}<0.05)$ only for the rack average absolute values. Warm carcass, right and left halves, leg, rack and plate, performed highest values in Group B. Most of the lowest values were recorded by the control group in warm carcass, right and left halves, leg, neck and shoulder and brisket and foreshank. For the percentages, values of the different cuts in treatment groups were following an irregular pattern.

The wholesale cuts values reported by [17] and Hassan [18] for Sudan Desert lambs agreed with the findings reported in this study for most components. Variations may be due to age, initial live weights and differences in managerial techniques.

Table-5 shows average subjective assessment values of meat quality attributes of lambs fed different levels of sugar beet bulb for 70 days.

Group A had the best tenderness $(100 \%)$ while a least tenderness attribute (80\%) was for groups $\mathrm{C}$ and D. For flavor and color percent, all groups are equal at
$100 \%$. For juiciness, percentages recorded were 93.3 and $86.70 \%$ for groups A and B respectively. Groups $\mathrm{C}$ and $\mathrm{D}$ are equal in values $(80 \%)$. Meat quality attributes are well tied to carcass yield. Most of these attributes are functions of breed type, carcass weight and the degree of fatness. Fat pressure starts at the intracellular level, intercellular and finally the extracellular. Factors influencing and determining the meat quality attributes are well overviewed by [19].

\section{Conclusions}

It is concluded from study results that replacing sorghum grains with Sugar Beet bulb can reduce mutton production cost without significantly affecting lamb carcass traits and meat attributes up to $22 \%$.

\section{Acknowledgements}

The authors are grateful to University of Gezira for permission and support of this work. Dean faculty of animal production and manager of Rural and Development center are also acknowledged for providing the experimental house.

\section{Competing interests}

The authors declare that they have no competing interests. 


\section{References}

1. A.O.A.D. (2009): Livestock number. ArabAgricultural Statistics year book volume No.29, Khartoum, Sudan.

2. Abd-Alrahman, A. M and Ahmed, S. S. (2005): Principles of Animal Production Science (In Arabic) $1^{\text {th }}$ edition publisher: Open University of Sudan, P.P.:388.

3. Moustafa, S.M.S., Mahgoub, A.A.S., Sallam, M.T., Abd El-Ghani ,A.A. and Mutonyi , J., Chebosi ,P. K. and Maguge, F. (2006): Preliminary observations on Sugar beet (Beta vulgaris saccharifera) grown at Mimias, Kenya. Proceeding South Africa sugar technology assembly, 80 pp. 136.

4. Gabra, M. A. and Gad, S. M. (1999): Physical characteristics and feeding values os some fodder beet varieties (Beta vulgaris L.) with reference of chopping size. Journal of Agricultural Science, Mansoura University, 24:3881-3890.

5. Mutonyi , J., Chebosi ,P. K. and Maguge, F.( 2006): Preliminary observations on Sugar beet (Beta vulgaris saccharifera) grown at Mimias, Kenya Proceeding South Africa sugar technology assembly, 80 pp. 136.

6. NRC. (1994): Nutrient Requirements of Beef Cattle (7th Ed.). National Academy Press, Washington, DC.

7. Smith, G. C. (1988): Yield of carcass and dress items and carcass quality-quantity measures of Angora and Spanish goats. Proceedings, 3rd Int. Conf., Production and Diseases. Tucson, Arizona, USA.

8. Mousa, M. R. M. (2011): Effects of feeding Acacia as supplements on the Nutrient digestion, growth performance, carcass traits and some blood constituents of Awassi lambs under the conditions of north Sinai. Asian Journal of Animal Science 5(2):102-117. http://scialert.net/abstract/?doi=ajas. 2011.102.117.

9. Tassoli, G. and F. Kafilzadeh. (2008): Effects of dried and ensiled Apple pomace from puree making on performance of finishing lambs. Pakistan journal ofBiological.science 11(2):294-29. http://scialert.net/ abstract/?doi=pjbs.2008.294.297.

10. Beshir, A. A, M. Y. Yagoub and S. A. Babiker. (2009): Performance of Sudanese Desert lambs fed graded levels of water melon (Citrullus lanatus) seed cake instead of groundnut cake. Pakistan Journal of Nutrition 8(5):525-529.http://scialert.net/abstract/ ?doi=pjn.2009.525.529.

11. Beshir, A. A. and S. A. Babiker .(2009): Performance of Sudanese Desert lambs fed graded levels of Roselle (Hibiscus sabdariffa) seeds instead of groundnut cake. Pakistan Journal of Nutrition 8(9):1442-1445. http:// scialert.net/abstract/?doi=pjn.2009.1442.1445.

12. Khadem, A. A. , M. Soofizadeh and A. Afzalzadeh (2007): Productivity, blood metabolites and carcass characteristics of fattening zandi lambs fed Sodium Bentonite Supplemented total mixed ration. Pakistan Journal of Biological Science 10(20):3613-3619. http://scialert.net/abstract/?doi=pjbs.2007.3613.3619.

13. Mansour, M. E., Sulieman, A. H.and Ali, T. E. (1993): The effects of breeds and different ratios of groundnut hay/Dura on the performance and carcass composition of Sudan desert sheep. Sudan Journal of Animal Production. 6:1-11.

14. Mansour, M. E., Sulieman, A. H., Ahmed, H. E. and Abd-Dalla, S. A. (1988): The effects of feeding complete rations comprising different levels of Groundnut hay on performance and carcass characteristics of Sudan desert lambs. Sudan Journal of Animal Production.1 (2):89-94.

15. Abdulkhalig, A. M., Meyer, H. H., Bushoom ,J. R., and Thompson, J. M. (2007): Growth, carcass and cocked meat characteristics of lambs sired by Dorset rams heterozygous for the Callipyge gene and Suffolk and Texel rams. Small Ruminant Research .71:92-97.

16. Bingol Mehemt, TurgutAygun, Ozdal Gokdal and Ayhan Yilmaz. (2006): The effects of docking on fattening performance and carcass characteristics in fat-tailed Norduz male lambs. Small Ruminant Research .64:101-106.

17. Galal, M. H. (1994): Meat Production and Quality of Sudan Desert Lambs. M.Sc. Thesis submitted to University of Khartoum, Sudan.

18. Hassan, E. H. (2005): The Effect of Feeding Rosells Seed (Hibiscus sabdariffa L.) on Meat Quality and Carcass Characteristics of Sudan Desert Sheep. M.Sc. Thesis, University of Gezira, Sudan.

19. Lawrie, R. A. (1991): Meat Science, 5th edition, Pergamon Press, Oxford. 